\title{
EDITORIALS
}

\section{Sun protection messages, vitamin D and skin cancer: out of the frying pan and into the fire?}

\author{
Monika Janda, Michael G Kimlin, David C Whiteman, Joanne F Aitken and Rachel E Neale \\ Expert guidance is needed to balance the benefits and risks of sun exposure
}

$\mathrm{V}$ itamin D (defined in this article as serum 25-hydroxyvitamin D) is largely obtained through the effect of sunlight on the skin. Vitamin D plays an undeniably important role in maintenance of bone health, preventing the development of rickets and osteomalacia. However, there has been increasing recent media attention given to research findings that suggest other possible benefits of vitamin $\mathrm{D}$, such as prevention of certain cancers or multiple sclerosis. ${ }^{1,2}$ In the first 6 months of 2006, seven of 124 daily updates on "cancer-related news" $(6 \%)$ monitored by The Cancer Council Australia featured at least one item on the importance of sun exposure for obtaining sufficient vitamin D to prevent chronic diseases. Given that the primary source of health information for most Australians is the media, ${ }^{3}$ such reports have the potential to change attitudes and behaviours to sun exposure.

Some commentators have compared doctors to sherpas who need to guide their patients through an increasingly complex medical world. ${ }^{4}$ The "vitamin D story", in which sun exposure appears to both cause cancer and prevent cancer, is one example where health consumers will need the guidance of health professionals in making an informed decision.

Since the 1980s, the "Slip! Slop! Slap!" and then the "SunSmart" campaigns have sought to reduce population exposure to sunlight with the ultimate aim of reducing the burden of skin cancer in Australia. ${ }^{5}$ The challenge, given current levels of evidence, is to provide a public health message that ensures skin cancer risk is minimised while taking a precautionary approach to the possible harms of insufficient circulating levels of vitamin D. Several agencies have initiated conferences and meetings within the past 2 years, resulting in articles recommending changes to current sunprotection messages, ${ }^{6-8}$ and in 2006, the first issue of the journal Progress in Biophysics and Molecular Biology was wholly devoted to ultraviolet (UV) radiation exposure guidance. In Australia, a position statement on the risks and benefits of sun exposure was approved in 2005 by the Australian and New Zealand Bone and Mineral Society, Osteoporosis Australia, the Australasian College of Dermatologists and The Cancer Council Australia. The statement's intention is to guide health professionals in giving information to the public on sun-protection behaviour. Four recommendations were made, and are summarised in the Box. ${ }^{9}$

Given the uncertainty about whether the subgroups within the population with the highest prevalence of vitamin D deficiency (the frail and elderly, people who cover themselves with clothing for cultural or religious reasons, those with dark skin pigmentation, those with mental illnesses) would benefit from a relaxation of sun-protection messages, each recommendation should be a starting point for further research. For example, considering the first recommendation (Box), the few studies available to date mostly indicate that, while most people are aware of the UV index, very few adjust their sun-protection behaviour accordingly. ${ }^{10-13}$ We need to determine ways to ensure that the UV index is routinely reported in weather forecasts in both summer and winter, and to increase public understanding of the implications of the UV index for sun-exposure behaviour. Additionally, it is likely that the association between the UV index and vitamin D production is not linear, and this needs to be explored in greater detail. ${ }^{14}$ Will the second recommendation (Box) lead to a more relaxed attitude towards sun protection in summer in the southern states? Basal cell carcinomas and squamous cell carcinomas most commonly occur on the habitually sun-exposed skin sites. ${ }^{15}$ While these skin cancers are rarely fatal, their treatment can require surgical or destructive intervention and cause considerable morbidity. ${ }^{16}$ An unintended consequence of the second recommenda-

Summary of the risks and benefits of sun exposure position statement*

- Sun protection is usually required if the ultraviolet (UV) index is 3 and above (and people are advised to check the forecast UV index in their local area).

- Most people achieve adequate vitamin D levels through incidental sun exposure, but people living in the southern Australian states in winter may need 2-3 hours of sun exposure on the hands, arms and face each week.

- Some people are at high risk of developing skin cancer and need more rigorous sun protection than the general population.

- Some subgroups of the population, such as the frail and elderly, and people who cover most of their body with clothing for cultural or religious reasons, may need to consult their doctor to have their vitamin D status investigated and supplemented if necessary.

* Modified from the full statement. ${ }^{9}$ 


\section{EDITORIALS}

tion might be to increase incidental sun exposure of the hands, arms and face and hence the incidence of skin cancer. Thus, the way this recommendation should be translated into a public health message needs careful consideration. For the third recommendation (Box), previous research has shown that people find it difficult to correctly assess their personal risk for skin cancer, ${ }^{17,18}$ and clinicians may need to help patients identify their risk. With regard to the fourth recommendation (Box), even though there is mandatory fortification of margarine in Australia, this is unlikely to achieve sufficient oral intake of vitamin $\mathrm{D}$, especially among those most in need, and further supplementation may be necessary. ${ }^{19}$ The acceptability and effect of fortification and supplementation among at-risk groups still requires testing, and other food sources suitable for fortification need to be identified.

At present, these complex recommendations are not being widely promoted to the general public, and further evidence on how to best communicate them is required, particularly in light of the media interest. Anecdotal evidence from the Queensland Cancer Fund suggests that the number of callers to their Helpline seeking advice about correct sun-protection behaviour is increasing. Further, unpublished data from a population-based survey conducted by the Queensland Cancer Fund in 2004 indicate that 837 of 5611 participants (15\%) agreed with the statement, "If I regularly protect myself from the sun, I am in danger of not getting enough vitamin D". ${ }^{20}$ These people were more likely to deliberately sunbathe than those who did not agree with this statement (odds ratio, 1.65; 95\% CI, 1.30-2.09). ${ }^{20}$

Assuming that the association between various chronic diseases and vitamin $\mathrm{D}$ can be unequivocally established, and that the appropriate vitamin D level and the UV radiation dose required to obtain it can be quantified — which is by no means certain - it still may not be possible to provide a single message about "healthy" sun exposure appropriate for the whole of Australia, a continent that spans more than 35 degrees of latitude. It has been estimated that only 6-12 minutes of winter sun exposure three to four times a week may be sufficient to produce "healthy" levels of vitamin D in Brisbane, compared with 51 minutes in Melbourne. ${ }^{21}$ Many factors in addition to latitude (age, skin type, sun-exposure habits, other skin cancer risk factors, photoprotection, body mass index, food choices, amount of physical exercise, liver and renal health, environmental conditions such as smog level, the season, and ozone levels) contribute to either people's risk of skin cancer or their ability to synthesise vitamin $\mathrm{D}$, or both.

More research is needed to better understand the photobiology of vitamin D formation in the skin, and the precise effect of UV radiation on vitamin $\mathrm{D}$ synthesis within various subgroups of the population. We don't yet know the minimum amount of sunlight needed to maintain healthy bones (let alone prevent internal cancers or chronic diseases, if indeed these benefits can be realised), nor whether these effects may not be better obtained through supplements. It is unlikely that the daily requirement for vitamin $\mathrm{D}$ could be obtained from foods fortified with vitamin $\mathrm{D}$ alone. ${ }^{22}$ A meta-analysis of randomised trials of vitamin D supplementation found that daily doses of 700-800 IU (17.5-20.0 $\mu \mathrm{g})$ reduced the incidence of fractures, but lower doses did not. ${ }^{23}$ Even after the answers to these fundamental research questions are known, translating these complex messages to the Australian public effectively will remain a challenge.

In the interim, the effect of current campaigns and media reports about vitamin $\mathrm{D}$ on sun-protective behaviours and sunburn rates should be monitored carefully, sun-safe practices should be encouraged, and supplements used where necessary until we increase our basic understanding of the relationships between chronic disease, vitamin D and sunlight. Sun exposure is the primary cause of skin cancer. If sun exposure and sunburn were to increase as a result of concern about the requirement for vitamin $\mathrm{D}$, several decades of effective public health promotion to reduce the incidence of the most common cancer in Australia would be jeopardised.

\section{Author details}

Monika Janda, MPhil, PhD, Research Fellow ${ }^{1,2}$

Michael G Kimlin, MAppSc, PhD, Senior Research Fellow ${ }^{2}$

David C Whiteman, FAFPHM, PhD, Senior Research Fellow ${ }^{3}$

Joanne F Aitken, MSc, PhD, Director ${ }^{1}$

Rachel E Neale, BVSc, PhD, Epidemiologist ${ }^{1,3}$

1 Viertel Centre for Research in Cancer Control, Queensland Cancer Fund, Brisbane, QLD.

2 Institute of Health and Biomedical Innovation, Queensland University of Technology, Brisbane, QLD.

3 Population Studies and Human Genetics, Queensland Institute of Medical Research, Brisbane, QLD.

Correspondence: m.janda@qut.edu.au

\section{References}

1 Garland CF, Garland FC, Gorham ED, et al. The role of vitamin D in cancer prevention. Am J Public Health 2006; 96: 252-261.

2 Wolpowitz D, Gilchrest BA. The vitamin D questions: how much do you need and how should you get it? J Am Acad Dermatol 2006; 54: 301-317.

3 Chapman S, Lupton D. The fight for public health. Principles and practice of media advocacy. London: BMJ Publishing Group, 1994.

4 Eaton L. A theme issue for medics and an increasingly health informed public. BMJ 2002; 325: 984

5 Montague M, Borland R, Sinclair C. Slip! Slop! Slap! and SunSmart, 1980 2000: skin cancer control and 20 years of population-based campaigning. Health Educ Behav 2001; 28: 290-305.

6 National Cancer Control Initiative. Sun and health. A summary of the expert meeting held on 15th July 2004 at the Cancer Control Research Institute of The Cancer Council Victoria. Melbourne: NCCl, 2004. http:// www.ncci.org.au/pdf/Sun\%20and\%20Health/wshop_report.pdf (accessed Oct 2006).

7 Lim HW, Gilchrest BA, Cooper KD, et al. Sunlight, tanning booths, and vitamin D. J Am Acad Dermatol 2005; 52: 868-876.

8 North American Conference on UV, Vitamin D and Health. UV, vitamin D and health key messages. 25 May 2006. http://www.cancer.ca/vgn/images/ portal/cit_86751114/3/10/1057720525cw_letterhead_key_messages_ en.pdf (accessed Oct 2006).

9 Risks and benefits of sun exposure: position statement. 8 Mar 2005. Approved by the Australian and New Zealand Bone and Mineral Society, Osteoporosis Australia, Australasian College of Dermatologists and The Cancer Council Australia. http://www.cancer.org.au/documents/Risks_ Benefits_Sun_Exposure_MAR05.pdf (accessed Oct 2006).

10 Blunden A, Lower T, Slevin T. Knowledge, awareness, and use of the UV index among the West Australian public. J Health Commun 2004; 9: 207221.

11 Alberink AM, Valery PC, Russell A, Green A. Do forecasts of UV indexes influence people's outdoor behaviour? Aust N Z J Public Health 2000; 24: 488-491.

12 Geller AC, Hufford D, Miller DR, et al. Evaluation of the ultraviolet index: media reactions and public response. J Am Acad Dermatol 1997; 37: 935941.

13 Branstrom R, Ullen H, Brandberg Y. A randomised population-based intervention to examine the effects of the ultraviolet index on tanning behaviour. Eur J Cancer 2003; 39: 968-974.

14 Kimlin MG, Downs NJ, Parisi AV. Comparison of human facial UV exposure at high and low latitudes and the potential impact on dermal vitamin $D$ production. Photochem Photobiol Sci 2003; 2: 370-375. 


\section{EDITORIALS}

15 Staples MP, Elwood M, Burton RC, et al. Non-melanoma skin cancer in Australia: the 2002 national survey and trends since 1985. Med J Aust 2006; 184: 6-10.

16 Rubin Al, Chen EH, Ratner D. Basal-cell carcinoma. N Engl J Med 2005; 353: 2262-2269.

17 Eiser JR, Pendry L, Greaves CJ, et al. Is targeted early detection for melanoma feasible? Self assessments of risk and attitudes to screening. J Med Screen 2000; 7: 199-202.

18 Melia J, Harland C, Moss S, et al. Feasibility of targeted early detection for melanoma: a population-based screening study. Br J Cancer 2000; 82: 1605-1609.
19 Nowson CA, Margerison C. Vitamin D intake and vitamin D status of Australians. Med J Aust 2002; 177: 149-152.

20 DiSipio T, Rogers C, Newman B, et al. The Queensland Cancer Risk Study: behavioural risk factor results. Aust N Z J Public Health 2006; 30: 375-382.

21 Samanek AJ, Croager EJ, Gies P, et al. Estimates of beneficial and harmful sun exposure times during the year for major Australian population centres. Med J Aust 2006; 184: 338-341.

22 Johnson MA, Kimlin MG. Vitamin D, aging, and the 2005 Dietary Guidelines for Americans. Nutr Rev 2006; 64: 410-421.

23 Bischoff-Ferrari HA, Willett WC, Wong JB, et al. Fracture prevention with vitamin $D$ supplementation: a meta-analysis of randomized controlled trials. JAMA 2005; 293: 2257-2264. 